\title{
What Is Culture? Toward Common Understandings of Culture in HCI
}

\author{
Anette Löfstrom \\ ITC, Lägerhyddsvägen 2, Hus 175237 Uppsala \\ anette.lofstromait.uu.se
}

\begin{abstract}
What is culture in HCI? This article presents how the term culture has been used and discussed by authors in the discipline. Since culture is a complex concept, there is no aim to establish the term as a fixed definition in this paper. Instead the purpose is to enlighten some previous discussions and uses in order to ask questions, encourage new discussions and give motivation for searching common understandings of the term culture among HCI researchers. This article also includes a discussion of how such a change can be launched. Geert Hofstede's thoughts about culture are discussed out of a complementary perspective and a suggestion to use the dimensional thoughts on different cultural and societal levels is given. Notably, this paper does not answer questions. It asks them.
\end{abstract}

Keywords: Culture, HCI, Hofstede.

\section{Introduction}

The idea to this paper evolved during the Interact Conference in Uppsala, Sweden 2009. Throughout a two day long workshop "Culture and Technologies for Social Interaction" the participants discussed and elaborated on culture and technology for social interaction. Suggestions of what culture really is were conferred but there was great confusion, and common understandings were not even close to be established. Thus, in spite the number of cultural focused studies in HCI general interpretations still seems to be lacking. Therefore, the aim of this paper is to encourage discussions that focus on potential common understandings of culture in HCI. Further more, I argue for using eventual similarities and coherences between different scientific fields and on different analytical levels to increase cooperation. The contribution is questions that can provide fuel to those discussions. This is important since common understandings of culture would ensure similar intentions and interpretations among culturally focused researchers in HCI. Further more, suggested questions are based on previous HCI literature. Moreover, because the cultural thoughts of Geert Hofstede have had great impact on our field, this will be discussed among critical arguments against his cultural model. Adding this, a suggestion of using his thoughts about cultural dimensions on different societal and analytical levels will be presented. Choice of articles is due to their grade of inspiration for future discussions. 


\section{Previous Use of Culture in HCI Literature}

\subsection{Prior Overviews}

When studying use of the term culture in HCI it is relevant to start with representing findings in previous literature overviews. Torkil Clemmensen and Kerstin Roese present a summary of publications in culture and HCI after 1998 in their article "An overview of a decade of Journal Publications about culture and Human Computer Interaction" [1]. This article follows an overview of earlier years, made by Pia Honold [2]. The purpose of Clemmensen's and Roese's paper is to review current practices related to how HCI cultural issues are studied and to analyze problems with the measures and interpretation of these studies. The authors present three important findings:

1. Most papers did not have any model of culture, merely used the word culture.

2. Most studies were quantitative studies with more than 20 participants.

3. In most of the studies, a major consideration in the choice of participants was that they could speak English.

Those findings inspire me to ask the following questions:

- How does the described way of using culture without reflection of the terms' immanent meaning affect potentially common understandings in HCI?

- How can we work in order to link together quantitative uses of culture, for example nationalistic grounded assumptions in large studies, with qualitative methods like deep interpretations of a specific cultural loaded phenomenon?

I am aware that the goal related to the second question above might be difficult to achieve. Still I think it is valuable to at least strive for, because it facilitates increasing cooperation between qualitative use of culture (deep interpretations of specific phenomena) versus quantitative uses of culture (studies including lots of people and with general assumptions). For example, if we find one frequent interpretation of a specific cultural loaded symbol on a basic level in different areas of HCI, maybe we can accept it as general? If so, this interpretation can be implemented on higher quantitative levels. This would ensure qualitative grounds in quantitative research and the other way around, qualitative focused researchers could strengthen their result by relating it to quantitative studies build on the same deep understandings as their own. Still this process should begin by searching common meanings in specific cultural loaded phenomena. Therefore, I suggest that linking qualitative interpretations with quantitative uses of culture should start in small scale and there after expand. These thoughts are similar to the ones discussed in an article presented by Singorini, Wiesemes and Murphy [3]. They advocate approaching culture by starting with examining micro- cultures in order to develop small models which can gradually be expanded in to larger models of culture. Their suggestion is a reaction against the national focused, criticized but often used cultural thoughts of Geert Hofstede.

\subsection{Geert Hofstede, Critique and Possible Use}

Singorini, Wiesemes and Murphy describe the five cultural dimensions used as analytical tools in Hofstede's work. They also discuss why they regard the dimensions as problematic and their opinion is quite extensive. One critique is that Hofstede 
overstates the effects of individualistic versus collectivistic nations and, following this, neglects other explanations for educational differences such as socio-economic factors, funding for educations etc. Moreover, the authors conclude that Hofstede uses the term in-groups without defining what it is; that he regards culture as something static; that differences more than similarities is focused and that his model can't be related to cultural complexity. However, in spite of the critique his model is frequently used. Myers and Tan listed 36 studies and 24 of those used Hofstede's dimensional thoughts [4].

Rachel F. Baskerville is another researcher offering critique against Hofstede. In an article called: "Hofstede never studied culture" [5] she identifies the following problems:

1. An assumption of equating nation with culture

2. The difficulties of, and limitations on, a quantification of culture represented by cultural dimensions and matrices

3. The status of the observer outside the culture

Hofstede made a reply on Baskerville's critique in a paper called: "What is culture? A reply to Baskerville" [6]. Here he claims that Baskerville did not read his work carefully and that she replicated parts of his work that failed to produce the same differences between countries. He also writes that his work has rarely been cited by sociologists and anthropologists who, he writes, are the ones that know about culture. At Baskervilles questioning if dimension indices that correlate with the result of other cross-national studies really are cultural dimensions he writes that whatever the dimensions are called they are the ones accounting research is interested in. He ends this argument with the following words:

"Most accounting researchers couldn't care less about what anthropologists call what- as little, by the way, as anthropologists care about accounting research" [6].

This quote motivates one of the meanings of this paper; to search for similarities and coherences between different scientific fields. I argue that searching cooperation's and mutual understandings between different research fields would increase scientific development. This leads to the following questions:

1. Is it possible that researchers who "couldn't care less" what researcher from other fields call what can meet and enrich each other scientifically? If so, how?

2. What would be the effects of such cooperation's?

However; in spite her critical standpoints Baskerville writes that: "It is not the wide application of Hofstede's framework that makes it good. Rather it is usefulness of the theories as mechanism of describing and understanding cultural diversity that makes them interesting and viable" [5]. Baskerville continues by claiming the need for developed theories and that Hofstede's work can facilitate this. I agree with this conclusion. Still I do not want to take a position in the debate "for or against" Hofstede since my personal scientific view is that quantitative and qualitative methods and their related theories are complementary and equally important. In quantitative cultural related studies it might be hard to avoid what Hofstede has been criticized for (static cultural view, national or general focused cultural assumptions etc.) Still such 
examinations are valuable since they provide knowledge on a general societal level. At the same time it is essential to analyze culture as dynamic and multi-facetted. Out of this reasoning and with Baskerville's claim of the value of providing theories as ground I suggest using Hofstede's cultural dimensions on different levels. However, I do not want my theoretical suggestion to be regarded as a way of "choosing side", because it is not. Rather it is a way of testing my view that quantitative versus qualitative focused scientific fields is mutually dependent and that they could enrich each other. Why not search for theoretical similarities and possibilities? The questions below could serve this purpose:

- Can Hofstede's thoughts of cultural dimensions be used as analytical tools on different levels and thereby work as glue between deep and general levels?

- How would such use of Hofstede's dimensions affect common understandings of culture in $\mathrm{HCI}$ ?

I demonstrate my thoughts in the model below:

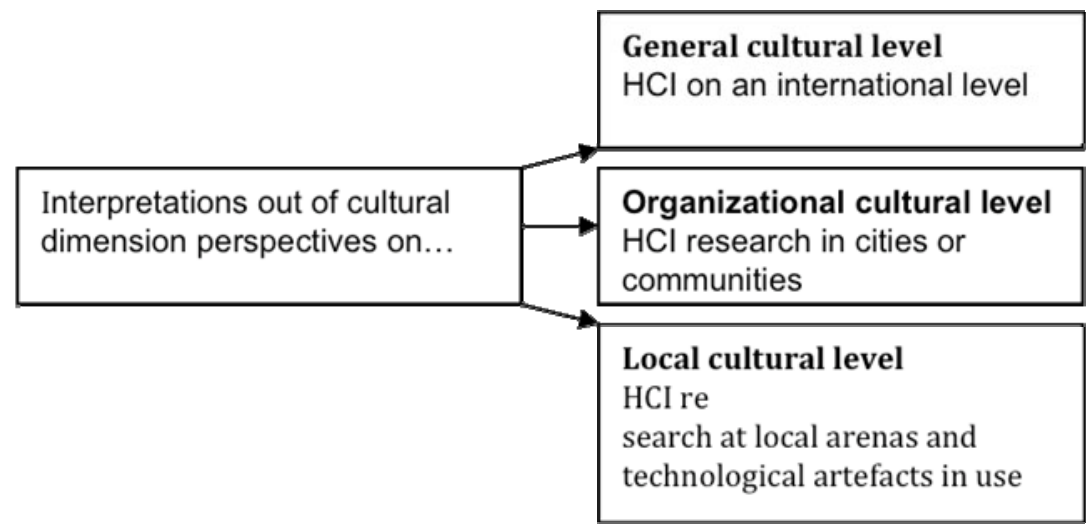

My view is that if interpretations out of the five dimensions on all three levels above reveal similarities, those could be used as one way to find common understandings of culture in HCI since the result would be usable for both quantitative and qualitative focused researchers.

After this discussion I will continue by discussing some examples of how culture has been used in HCI.

Examples of culture use in HCI

When looking back at previous studies of culture, it seems that the cultural perspective in HCI has increased. M., Kamppuri, R., Bednarik, M.,Tukiainen claim that articles in our field considering national/ethnic culture were rare in the first half of the 1990's. They also write that:

Even though the total number of HCI articles has (...) grown during the later half, it is only about 1.2 times greater compared to the earlier half, whereas the number of culture related articles is six times greater compared to the earlier half [7].

Hence, it seems that the general interest of culture in the field has enlarged. Still there is a difference in the author's presentation above that needs to be noticed. In the first 
half of the 1990: s the authors speak about national/ethnic culture whereas they do not use this delimitation in the quote about the latter half of the 1990: s. Here they say "culture related articles" rendering possible for alternative interpretations of what culture really is. This could serve as an example of the immanent complexity in the term. It can also be used as a foundation for discussion, searching for an answer of the question:

- How can HCI researchers identify and avoid pitfalls that emanates from cultural complexity?

So far we have seen that many studies using cultural perspectives are quantitative. One example of this is a study of Ravi Vatrapu and Dan Suthers [8] who wrote an article where they aimed for a systematic examination of phenomena in the nexus of culture, technology and learning. Their assumption was that social affordances of technology might vary along cultural dimensions. They describe culture as patterns or schemas even if phenomena like symbols, rituals, norms, values and practices cover the most visible manifestation of culture. Those authors describe culture as something shared and as factors in individuals' social interactions. Culture is used as cognitive schemas that are formed from an individual's biography which includes interactive effects of geography of that individual's upbringing and the formative experiences of his/hers life. They argue that cultural models can be used to identify differences in culture that affect computer supported collaborative learning environments and they group the concept of culture in four of Hofstede's dimensions [8]. As shown Vatrapu and Suthers discuss cultural schemas (quantitative methods) while still including basic cultural issues such as rituals and symbols. This can serve as an example that linking quantitative uses with qualitative interpretations might be reachable. Still I want to point out the essential difference between this article and my scientific view. Vatrapu and Suthers argue that cultural models can be used to identify differences while I suggest using them to find similarities. Questions emanating out of this reasoning are:

- Would it affect common understandings of culture if we seek similarities instead of differences?

- What difficulties are we likely to face when analyzing basic phenomena, like for example effects of norms on technology use, and relate it to analysis on general levels?

- What are the potential benefits of such an approach?

Researchers claiming that approaches which take culture explicitly into account may add valuable contributions to the design and evaluation of effective online communities are Clarissa Barbosa, Carla Leitao and Clarisse de Souza [9]. They show how HCI researchers handle cultural dimensions in online communities in different ways. Focusing Brazilian people's way of living in informal social relationships and by observing that this people prefer to get information by exchanging messages with each other rather than searching it on the web these researchers studied how informality in daily life affected Brazilians online community activities.

My interpretation of this is that in the study above culture is used practically by studying daily life habits and transforming theme into online activities. The cultural perspective used is ethnicity (Brazilian). A common perspective among ethnologists 
is that ethnicity is based on identity, both by people belonging to a group to be an "us" and by other to group those people to "the others". Another ordinary view is that identifications phenomena such as loaded symbols, things and stories are used to shape a sense of fellowship with other members of the group. I suggest that this is important to regard when following the authors claims that: "cultural characteristics may be crucially important requirement for developing effective technology" [9]. They also emphasize that HCI professionals should: "investigate the cultural characteristics of communities' one design for, and comprehend their impacts both on the technological design and the subsequent success of online communities" [9]. I suggest that what these authors call cultural characteristic might be manifested in basic phenomena like symbols, heroes, rituals and values. Further more, in HCI I argue for regarding technological devices as cultural arenas as well since most technologies are designed with cultural loaded phenomena in the interfaces. Therefore, my next thought in this paper is that cultural focused researchers in our field might discover new cultural phenomena or even categories that are based in the technology. This reasoning leads to the questions:

- Are there any new cultural phenomena or categories in the technology, if we regard it as a cultural arena in it self? If so, how do we connect those categories with real life?

- Are such eventual phenomena or categories beneficial or do they make the concept of culture even more complex?

My view is that even if culture constitutes a central framework in the article above it is still difficult for a designer to know which identification is the main factor in the actual situations and tasks of the user. Therefore, I agree with the authors when they say that "shifting focus from capturing to understanding culture" [9] is important. This leads to the following questions:

- How do we know which cultural phenomena in real life are most essential to address for designers?

- What tools do we need for valuing the importance of different cultural elements for different kinds of designs?

However, if we manage to understand culture in a similar way in the future we face the next obstacle.

- How do we implement new cultural knowledge in design processes?

Ashwini Asokan writes that: "CHI community is still sparse on conversations and significance of world cultures on design and HCI" [10]. Despite the enlightened delimitation the author gives the following valuable description of culture as:

a lifestyle, a set of beliefs and value systems that shape every day life in countries around the world, is at the core of understanding what our community calls the 'user'. It is in the context that explains all data and inspiration we use in our design and creative process [10].

Further more, Asokan's regards culture as highly context dependent. This assumption is important since every single person lives in different contexts and is affected of them all which mean that even if the specific context in the precise user situation is of 
extremely importance reality is much more complex than that when working with people and their interaction with technology. Let us suppose that the user had a bad morning with stress, sick children, broken car and delayed bus. It is likely that those circumstances lead to variations in contexts effects on the user and in the next step the user's perception and use of the technological device. This arguing leads us to another essential perspective. Among ethnologists humans are regarded and interpreted as "cultural beings" that both affects and is affected of tremendously many factors. Therefore I argue that the suggested contextual understanding of culture is extremely important but it should be complemented with the equally important view of humans as cultural beings since the "cultural human" affects technology use. In her conference contribution Asokan asks the question: "At an organizational and management level, what do we require to ensure integration of culture into our practice" [10]. Maybe interpreting users as cultural beings on a deep analytical level and relate the result to general (for example organizational and management) levels is one way to do this? However, a central perspective here is that Asokan understands culture as context dependent which leads to the following questions:

- What divides culture from context in HCI?

- If culture is context dependent, is context dependent of culture as well?

- How do these eventual dependencies affect technology designs and uses?

In their article Culturability: The Merging of Culture and Usability Wendy Barber and Albert Badre uses the term "cultural context". They write that: "As a consequence of existing international WWW users (...), usability takes on immediate and relevant cultural context" [11]. In this study the authors identifies what they call localisation elements and generalize them into "cultural markers" that are specific to a given culture and/or perhaps influenced by genre. They define cultural markers as design elements found in web pages and which prove highly prevalent within a particular cultural group and less prevalent or absent in another group. Usability issues are central in their study and cultural preferences and biases such as colours and spatial orientation among others impact what is deemed as user friendly [11].

Barber and Badre provide the reader with an explicit description of how they use the term culture. They write that: "We use the word "culture"- somewhat loosely- as a means of distinguish among the different countries and their respective websites" [11]. They use the term out of an ethnic perspective but with a consciousness of the terms complexity since they say that: "our use of the term is not intended to be inductive of all the nuances and properties frequently applied by the term" [11]. So, those authors make clear what culture is in this specific study. They want to permit a discourse that distinguishes one country or region of the world from another. In this case culture is used as boarder markers such as national symbols, colour or spatial organizations that are preferred by specific groups of users. Relating this study to Hofstede's cultural thoughts and my own suggestion to interpret culture in a similar way on different levels I ask the following question:

- How would cultural similarities on different levels affect designs?

Adding this I want to point out that what is obvious but implicit in this study is the great importance of symbols. The authors search "cultural markers" but if those were not loaded with symbolic meanings they would be useless in a cultural conscious 
design process, because they would not send a message to the user. They would just be there. For example, when designers use flags for choice of language. If the flags were not loaded with symbolic meaning the user would not know what flag to click for a certain language Therefore the article above is an example of research using cultural phenomena on a basic level (symbols) to distinguish cultures on a general level (nationality). However, there is a crucial difference between my theoretical suggestion in this paper and Barber's and Badre's article. They use basic symbols for distinguish on the general level while my suggestion is not to distinguish but instead search similarities and coherences.

\section{Discussions}

In this paper I have searched in HCI literature for presentations grounding questions about what culture really is in our research area. One common use of culture I have found is that the authors discuss phenomena typical regarded as culture such as symbols, values, rituals and norms. This inspires me to ask:

- What would be the result if designers used typical cultural phenomena as analytical tools for understanding technological devices in the same way that he or she interprets the user context in the iterations of the design process?

Ethnicity and nationality seems to be an often used cultural perspective. Still I suggest that HCI researchers should be open for other equally significant perspectives on general levels. Therefore I want to ask the following questions:

- How can we evaluate which characteristics on different cultural levels have the greatest significance when designing for a specific situation, task, context and user?

- How do we know what cultural issues are most important if the same technological device is to be used in different cultural contexts and by users with different cultural backgrounds and experiences?

Further more, in this paper I argue for striving towards common understandings of culture in HCI. Still, some readers of this paper might not agree with the need of such commonality. If so I suggest the following question.

- Are there any disadvantages with common understandings of culture in HCI? Is it worth striving for? Why or why not?

Finally, my personal point of view is that common understandings of culture definitely are worth striving for. I argue that if every author has at least some common understandings which are relevant for HCI it would ensure similar intentions when using the term culture and corresponding reader interpretations independent of the researcher's different educational backgrounds and choice of methods and theories. We would know what elements must be included when a conference topic contains "cultural issues". My suggestion to use Hofstede's cultural dimensions in different levels is one way to facilitate this. Beside these arguments there can be more benefits that my discussion in this article does not reveal. Therefore the last question I suggest is:

- What are the benefits of shaping common understandings of culture in HCI? 


\section{Conclusions and Future Work}

In this paper I have raised questions to bring into the discussion about the concept of culture in the HCI discourse. I have also argued for cooperation's between different scientific fields in our research area.

This conference contribution shall be regarded as an inspiration for future work and as the beginning of an iterative process similar to those that are usual for technology development in HCI. The difference is of course that in this work the iterations occur between researchers developing a general "usability" of a complex but often used term. Therefore I plan to utilize the discussions this article grounds as empiric material in an iterative process, that is to say, to continue writing articles building on HCI researcher's understandings and uses of culture. Beside this, workshops and tutorials on conferences can be innovative for this purpose as well. Finally, this future studies and discussions of culture will be linked to my own research that is an examination of web based cooperation's in the City of Stockholm. My focus is on leader strategies and employees driving forces to use the web for communicating with leaders. One important question in this research is how culture affects such work.

\section{References}

1. Clemmensen, T., Roese, K.: An overview of a decade of Journal Publications about culture and Human Computer Interaction. Workingpaper nr. 03. Copenhagen Business School (2009)

2. Honold, P.: Learning how to use a cellular phone: Comparison between German and Chinese users. Technical Communication 46(2), 196-205 (1999)

3. Signorini, P., Wiesemes, R., Murphy, R.: Developing alternative frameworks for exploring intercultural learning: a critique of Hofstede's cultural difference model. Teaching in Higher Education 14(3), 253-264 (2009)

4. Myers, M.D., Tan, F.B.: Beyond Models of National Culture in Information System Research. In: Advanced Topics. Information Management, vol. 2 (2003)

5. Baskerville, R.F.: Hofstede never studied culture. Accounting, Organizations and Society $28,1-14(2003)$

6. Hofstede, G.: What is culture? A reply to Baskerville. Accounting, Organizations and Society 28, 811-813 (2003)

7. Kamppuri, M., Bednarik, R., Tukiainen, M.: The expanding Focus of HCI: Case Culture. In: NordiCHI (2006)

8. Vatrapu, R., Suthers, D.: Culture and Computers: A review of the Concept of Culture and Implications for Intercultural Collaborative Online Learning (2007),

http: / / www. springerlink. com/ravivatrapu

9. de A., Barbosa, C.M., Leitao, C.F., de Souza, C.S.: Why Understanding Culture is Important for Developing Effective Online Health Support: the Brazilian Context. In: International Conference on Human-Computing Interaction (2005)

10. Asokan, A.: Culture Calling: Where is HCI? In: CHI Proceedings (2008)

11. Barber, W., Badre, A.: Culturability: The Merging of Culture and Usability. In: 4th Conference on Human Factors and the Web (1998) 